\title{
Meddling with new technologies or amending an embryos' potential
}

\author{
David F. Albertini ${ }^{1}$
}

Published online: 24 April 2019

(C) Springer Science+Business Media, LLC, part of Springer Nature 2019

" $[\mathrm{I}] \mathrm{t}$ is not hypothesis-driven research, itself, that I have ever favored but rather those hypotheses that can be tested by experiment. I am in favor of human intervention by thought and deed."

-Sydney Brenner

Sydney Brenner, who just passed away at age 92, was for many experimentalists the founder of the notion of animal model systems as both guide to the understanding of complex mechanisms underlying human development and disease, and as gatekeeper for recognizing at what point a model system begins to fail the experimentalists' hopes and expectations (https://www.the-scientist.com/news-opinion/sydneybrenner\%2D\%2Dmrna-discoverer\%2D\%2Ddies-65708). Among his seminal contributions was the introduction of Caenorhabditis elegans as a model system for many things developmental. And the experimental tractability of worms has fostered many fundamental advances in eukaryotic gametogenesis and embryogenesis through the efforts of his proteges, some of which provided insights into the human condition. Upon receipt of the Nobel Prize in 2002, he made the above statement in the context of the then-emerging field of "omics," cautioning the scientific community that the seductive influence of big data gathering and its default analysis by the nascent discipline of bioinformatics would compromise sapiens-based curiosity, passion, and critical thinking-all hallmarks of the experimentalist he exemplified.

Not only has our preoccupation with "omics" continued to meddle with the imperfections of scientific inquiry driving past and present ARTs (consonant with the woeful inadequacies of Homo sapiens as a tractable experimental model itself)

David F. Albertini

eicjarg@gmail.com

1 Center for Human Reproduction, New York, NY, USA at the levels of discovery and implementation, but a new dimension of research is rearing its ugly head all too prominently in the field of reproductive medicine: artificial intelligence (AI).

As a point of departure for this issue of JARG, we encourage our readership to consider the thought-provoking and prescient look at AI provided by Curchoe and Borman (Artificial intelligence and machine learning for human reproduction and embryology presented at ASRM and ESHRE 2018https://doi. org/10.1007/s10815-019-01408). They call for a heightened awareness, and critical appraisal of the tools from AI and machine learning already being touted as "ready for prime time" in human ARTs. That validations of technology platforms in our field tend to be events that follow the rush to implementation is already a sadly distinguishing character trait that best be avoided for all if we are truly in the business of improving our treatment strategies for infertile or subfertile patients.

There are warning signs evident given the backdrop of addons that have forged their way into the vernacular and practice of human ARTs. AI too is poised to assume its dutiful position should such trends continue. Heeding the warning signs being adopted by other biomedical disciplines would be well worth our efforts now as Curchoe and Borman argue in their article, and would place us within a jurisdiction being more broadly recognized elsewhere [1].

A most relevant case in point is that of embryo selection and the ongoing conversation over exactly who in the final analysis will benefit from the use of PGT-A. Over and above the fact that human embryos seem to carry with them some very "sloppy" or deficient governing systems to fight against their propensity to chromosomal errors [2], this issue draws attention to some aspects of PGT-A that have been overlooked on the trail to current day practices and requires that the burden of proof rest again in the validation strategies that may in the past have missed important consequences that most influence the spectrum of conditions we seek to diagnose and treat. For example, with single embryo transfer (SET) now plainly in view, wondering about live birth outcomes (LBR) 
following biopsy can be teased apart with much greater resolution than that used by the technology's forebears. From last month's issue, this was exactly the subject of the paper by Coetzee and colleagues that found whether or not PGT-A was done in a controlled SET setting did not matter in terms of LBR outcomes [3]. Extending this approach to the use of vitrified blastocysts, some benefit of PGT-A accrues in a recent study; outcome data at the level of LBRs is wanting to date, but will hopefully define some level of benefit in the decision-making for what patients are most likely to gain from PGT-A [4] as other encouraging results indicate [5].

This is all well and good as far as the predictive value of LBR after PGT-A as we hone in on the best-case scenarios and applications from the perspective of patients that will obtain significant benefit. But, in all fairness, can we say we have truly settled this technology out when we speak of safety, efficiency, and cost? Apparently not.

Singh and colleagues take a close look at the intrinsic property of blastocysts with respect to the endogenous ability to initiate and sustain hatching [6]. Surprisingly or not, they report that outcomes are very different depending on whether the embryo was hatching on its own or not! While retrospective and observational, this is the kind of insight that we have yet to take into full consideration and raises important questions about how iatrogenic hatching may even conceal a dimension of embryo quality that would have manifested itself if we waited to conduct the biopsy. A corollary to this finding that has been hashed around for years now has to do with just how damaging is the biopsy itself? How many cells? Where are we taking them from? How well does a biopsied blastocyst recover after iatrogenically induced collapse?

That poking and prodding matter is well known to anyone that has conducted biopsies on day 5 and day 6 blastocysts. And if you believe in the results of Guzman and friends, how many cells you take will indeed influence outcomes [7]. And recovering from cryopreservation with respect to regaining the attribute of expansion also seems to be a determinant in the long-running saga of PGT-A, at least according to the study by Ferreux et al. [8]. What does this come down to?

To proponents of embryo selection not requiring the insults of artificial hatching and biopsy, the banner is indeed raised as media sampling of cell-free DNA or other biomarkers of embryo quality move closer to the bedside and with some luck, this would be a welcomed addition to the ART menu option. Perhaps it is time to adopt the notion of "kinder, simpler" to our micromanagement of the human embryo just as it was used in the context of ovarian stimulation in the past.

In closing, there was a time for many of us long before even the prospect of human ARTs was tenable, and these lyrics from 1967 (Buffalo Springfield, For What It's Worth) carried a message worth revisiting today:

"Something's happening here and what it is ain't exactly clear."

\section{References}

1. Yu KH, Kohane IS. Framing the challenges of artificial intelligence in medicine. BMJ Qual Saf. 2019;28:238-241. https://doi.org/10. 1136/bmjqs-2018-008551.

2. Lee A, Kiessling AA. Early human embryos are naturally aneuploidcan that be corrected? J Assist Reprod Genet. 2017;34(1):15-21.

3. Ozgur K, Berkkanoglu M, Bulut H, Yoruk GDA, Candurmaz NN, Coetzee K. Single best euploid versus single best unknown-ploidy blastocyst frozen embryo transfers: a randomized controlled trial. J Assist Reprod Genet. 2019. https://doi.org/10.1007/s10815-01801399.

4. Gorodeckaja J, Neumann S, McCollin A, Ottolini CS, Wang J, Ahuja $\mathrm{K}$, et al. High implantation and clinical pregnancy rates with single vitrified-warmed blastocyst transfer and optional aneuploidy testing for all patients. Hum Fertil (Camb). 2019;7:1-12. https://doi.org/10. 1080/14647273.2018.1551628.

5. Simon AL, Kiehl M, Fischer E, Proctor JG, Bush MR, Givens C, et al. Pregnancy outcomes from more than 1800 in vitro fertilization cycles with the use of 24-chromosome single-nucleotide polymorphism-based preimplantation genetic testing for aneuploidy. Fertil Steril. 2018;110(1):113-21.

6. Singh S, Hobeika E, Knochenhauer ES, Traub ML. Pregnancy rates after pre-implantation genetic screening for aneuploidy are only superior when trophectoderm biopsy is performed on hatching embryos. J Assist Reprod Genet. 2019. https://doi.org/10.1007/s10815019-01400.

7. Guzman L, Nunez D, Lopez R, Inoue N, Portella J, Vizcarra F, et al. The number of biopsied trophectoderm cells may affect pregnancy outcomes. J Assist Reprod Genet. 2019;36(1):145-51.

8. Ferreux L, Bourdon M, Sallem A, Santulli P, Barraud-Lange V, Le Foll N, et al. Live birth rate following frozen-thawed blastocyst transfer is higher with blastocysts expanded on Day 5 than on Day 6. Hum Reprod. 2018;33(3):390-8.

Publisher's note Springer Nature remains neutral with regard to jurisdictional claims in published maps and institutional affiliations. 